\title{
PRENATAL ULTRASONIC DIAGNOSIS OF OBSTRUCTIVE BOWEL DISEASE: A RETROSPECTIVE ANALYSIS
}

\author{
R. HEYDANUS, M. C. SPAARGAREN AND J. W. WLADIMIROFF
}

Division of Prenatal Diagnosis, Department of Obstetrics and Gynaecology, Academic Hospital Rotterdam-Dijkzigt, Rotterdam, The Netherlands

Received 22 November 1993

Revised June 1994

Accepted 7 June 1994

\begin{abstract}
SUMMARY
Fetal obstructive bowel disease was diagnosed in 29 patients at 22-37 weeks (median 32 weeks) of gestation, seven (24 per cent) of whom also displayed other anomalies. Polyhydramnios was present in 20/29 cases (69 per cent). An abnormal karyotype existed in $7 / 29$ cases (24 per cent), of which six were diagnosed prenatally (trisomy $21, n=5$; $69, \mathrm{XXX}, n=1$ ) and one postnatally (trisomy 21). There was always an association with the ultrasonic 'double bubble' sign. Obstructive bowel disease was confirmed postnatally in 20/29 (69 per cent) cases, i.e., oesophageal atresia $(n=1)$, duodenal obstruction $(n=12)$, and small bowel obstruction $(n=7)$. Other anomalies existed in $6 / 29(21$ per cent) cases, i.e., multicystic kidney $(n=1)$ and multiple congenital anomalies $(n=5)$. The perinatal mortality rate was 35 per cent $(7 / 20)$.
\end{abstract}

KEY WORDS-Fetus, obstructive bowel disease, karyotype, polyhydramnios.

\section{INTRODUCTION}

Fetal obstructive bowel disease represents a common group of congenital anomalies, with a reported incidence of 1 in 1500 live-births. Because of the obstructed passage of amniotic fluid through the fetal gastrointestinal tract, it is often associated with polyhydramnios and abnormal sonographic appearances inside the fetal abdomen. Previous reports on fetal obstructive bowel disease have established an association with chromosomal defects and poor fetal outcome. It is therefore essential to define ultrasound markers which will allow early identification of these anomalies.

The present study reports on the findings of 29 consecutive cases of prenatally suspected fetal obstructive bowel disease with emphasis on the accuracy of ultrasound markers, the incidence of chromosomal anomalies, and fetal outcome.

Addressee for correspondence: J. W. Wladimiroff, MD, Department of Obstetrics and Gynaecology, Academic Hospital Rotterdam-Dijkzigt, Dr Molewaterplein 40, 3015 GD Rotterdam, The Netherlands.

\section{MATERIALS AND METHODS}

During the period 1980-1992, fetal obstructive bowel disease was diagnosed in 29 patients who were referred to our level III centre at 22-37 weeks (median 32 weeks) of gestation for further assessment because of suspected structural pathology at the referring hospital. Maternal age varied between 17 and 39 years (median 28 years); maternal parity ranged between 0 and 3 (median 1).

The diagnosis of fetal obstructive bowel disease was suspected on (i) repeated absence or (ii) marked dilatation of stomach filling, (iii) the characteristic 'double bubble' sign, or (iv) dilated bowel loops. Polyhydramnios was defined as a large fluid pocket of $10 \mathrm{~cm}$ or more, oligohydramnios as a large fluid pocket of $1 \mathrm{~cm}$ or less. Intrauterine growth retardation (IUGR) was diagnosed when the upper fetal abdominal circumference was situated below the tenth centile of the reference curve (Campbell and Wilkin, 1975).

All fetal scans were performed using a Diasonics CV 100 (carrier frequency 3.5 and $5.0 \mathrm{MHz}$ ) or a Toshiba SSA 270 (carrier frequency $3.75 \mathrm{MHz}$ ). 
Table I-Prenatal data and fetal outcome in four fetuses with ultrasonically absent stomach filling

\begin{tabular}{lccccccc}
\hline Case No. & $\begin{array}{c}\text { Ultrasound examination } \\
\text { (weeks) }\end{array}$ & AF & $\begin{array}{c}\text { Prenatal } \\
\text { karyotype }\end{array}$ & $\begin{array}{c}\text { Delivery } \\
\text { (weeks) }\end{array}$ & Outcome & $\begin{array}{c}\text { Postnatal } \\
\text { karyotype }\end{array}$ & Diagnosis \\
\hline 1 & 35 & PH & - & 36 & Alive & - & TP \\
2 & 30 & PH & - & 31 & 7 month & n & mis MCA \\
3 & 36 & PH & - & 36 & IUD & - & mis MCA \\
4 & 35 & PH & m & 36 & 13 days & - & \\
\hline
\end{tabular}

$\mathrm{AF}=$ Amniotic fluid; $\mathrm{PH}=$ polyhydramnios; $\mathrm{n}=$ normal; $\mathrm{IUD}=$ intrauterine death; $\mathrm{TP}=$ true positive; mis=misclassification; $\mathrm{MCA}=$ multiple congenital anomalies.

Table II--Prenatal data and fetal outcome in four fetuses with ultrasonically dilated fetal stomach

\begin{tabular}{lccccccc}
\hline Case No. & $\begin{array}{c}\text { Ultrasound examination } \\
\text { (weeks) }\end{array}$ & AF & $\begin{array}{c}\text { Prenatal } \\
\text { karyotype }\end{array}$ & $\begin{array}{c}\text { Delivery } \\
\text { (weeks) }\end{array}$ & Outcome & $\begin{array}{c}\text { Postnatal } \\
\text { karyotype }\end{array}$ & Diagnosis \\
\hline 5 & 37 & $\mathrm{n}$ & - & 39 & Alive & - & TP \\
6 & 36 & $\mathrm{n}$ & - & 40 & Alive & - & FP \\
7 & 31 & PH & $\mathrm{n}$ & 37 & IUD & - & TP \\
8 & 30 & PH & n & 34 & IUD & - & FP \\
\hline
\end{tabular}

$\mathrm{AF}=$ Amniotic fluid; $\mathrm{n}=$ normal; $\mathrm{PH}=$ polyhydramnios; $\mathrm{IUD}=$ intrauterine death; $\mathrm{TP}=$ true positive; $\mathrm{FP}=$ false positive.

Fetal karyotyping was performed in 16 cases by means of amniocentesis $(n=14)$, transabdominal chorionic villus sampling (TA-CVS) $(n=1)$, or culturing fetal ascites $(n=1)$. In the remaining 13 cases, no fetal karyotyping was performed because of advanced gestational age ( $\geqslant 36$ weeks) at the time of referral $(n=5)$, premature labour $(n=5)$, or parental refusal $(n=3)$. Postnatal karyotyping because of multiple structural anomalies was carried out in five infants. Details on pregnancy outcome were obtained from clinical records or from autopsy at the referring hospital or our own centre.

\section{RESULTS}

Referral indications from the referring hospitals to our centre were dilated bowel loops or intraabdominal cystic structures $(n=12)$, polyhydramnios $(n=5)$, renal anomalies $(n=3)$, dilated fetal stomach $(n=2)$, absent fetal stomach filling $(n=2)$, severe IUGR $(n=2)$, multiple congenital anomalies $(n=2)$, and suspected intracranial pathology $(n=1)$.

In our centre the diagnosis of fetal obstructive bowel disease was based on repeated absence $(n=4)$ or marked dilatation $(n=4)$ of the fetal stomach, the presence of the typical 'double bubble' sign $(n=10)$, and dilated bowel loops $(n=11)$. Data on prenatal and postnatal findings as well as fetal outcome are presented in Tables I-IV.

In 22 cases obstructive bowel disease was the only anomaly, twice accompanied by IUGR (Nos. 10 and 29). In the remaining seven cases associated anomalies were seen, i.e., cardiac defects (Nos. 12 and 18), neural tube defects (Nos. 15, 16, and 20), skeletal anomalies (No. 9), and ascites (No. 21). Polyhydramnios was present in 20 cases, oligohydramnios in three cases, and in the remaining six cases the amniotic fluid volume was normal.

An abnormal karyotype existed in seven out of 29 (24 per cent) cases, of which six were diagnosed prenatally (trisomy $21, n=5 ; 69, \mathrm{XXX}, n=1$ ) and one postnatally (trisomy 21 ). All seven abnormal karyotypes were associated with the 'double bubble' sign and polyhydramnios.

In 27 cases, expectant obstetric management was followed. One pregnancy was terminated because of the abnormal ultrasonic findings early in pregnancy (No. 16) and another because of an abnormal karyotype revealed by amniocentesis (No. 9; triploidy). 
Table III-Prenatal data and fetal outcome in ten fetuses with ultrasonically 'double bubble' sign

\begin{tabular}{rccccccc}
\hline Case No. & $\begin{array}{c}\text { Ultrasound examination } \\
\text { (weeks) }\end{array}$ & AF & $\begin{array}{c}\text { Prenatal } \\
\text { karyotype }\end{array}$ & $\begin{array}{c}\text { Delivery } \\
\text { (weeks) }\end{array}$ & Outcome & $\begin{array}{c}\text { Postnatal } \\
\text { karyotype }\end{array}$ & Diagnosis \\
\hline 9 & 32 & PH & 69, XXX & 35 & TOP & - & TP MCA \\
10 & 25 & n & tri 21 & 33 & IUD & - & TP \\
11 & 36 & PH & - & 37 & Alive & tri 21 & TP \\
12 & 30 & PH & tri 21 & 34 & NND & - & TP \\
13 & 29 & PH & tri 21 & 31 & NND & - & TP \\
14 & 34 & PH & tri 21 & 36 & Alive & - & TP \\
15 & 36 & PH & $\mathbf{n}$ & 37 & NND & - & TP MCA \\
16 & 22 & oligo & $\mathbf{n}$ & 23 & TOP & - & TP MCA \\
17 & 32 & PH & - & 34 & Alive & - & TP \\
18 & 31 & PH & tri 21 & 38 & Alive & - & TP \\
\hline
\end{tabular}

$\mathrm{AF}=$ Amniotic fluid; $\mathrm{PH}=$ polyhydramnios; $\mathrm{n}=$ normal; oligo=oligohydramnios; tri $21=$ trisomy $21 ;$ TOP=termination of pregnancy; IUD=intrauterine death; $\mathrm{TP}=$ true positive; $\mathrm{MCA}=$ multiple congenital anomalies.

Table IV-Prenatal data and fetal outcome in 11 fetuses with ultrasonically dilated bowel loops

\begin{tabular}{lccccccc}
\hline Case No. & $\begin{array}{c}\text { Ultrasound examination } \\
\text { (weeks) }\end{array}$ & AF & $\begin{array}{c}\text { Prenatal } \\
\text { karyotype }\end{array}$ & $\begin{array}{c}\text { Delivery } \\
\text { (weeks) }\end{array}$ & Outcome & $\begin{array}{c}\text { Postnatal } \\
\text { karyotype }\end{array}$ & Diagnosis \\
\hline 19 & 34 & PH & - & 35 & Alive & - & TP \\
20 & 35 & $\mathbf{n}$ & - & 35 & Alive & - & TP \\
21 & 31 & $\mathbf{P H}$ & - & 34 & Alive & - & TP CF \\
22 & 35 & $\mathbf{P H}$ & - & 37 & Alive & - & FP \\
23 & 32 & $\mathbf{P H}$ & $\mathbf{n}$ & 38 & Alive & - & TP \\
24 & 33 & $\mathbf{P H}$ & $\mathbf{n}$ & 38 & Alive & - & TP \\
25 & 31 & $\mathbf{P H}$ & $\mathbf{n}$ & 35 & Alive & - & TP \\
26 & 22 & oligo & - & 25 & IUD & - & mis MCA(R) \\
27 & 35 & n & $\mathbf{n}$ & 39 & Alive & - & mis R \\
28 & 22 & n & $\mathbf{n}$ & 36 & Alive & - & TP \\
29 & 30 & oligo & - & 36 & Alive & $\mathbf{n}$ & mis MCA \\
\hline
\end{tabular}

$\mathrm{AF}=$ Amniotic fluid; $\mathrm{PH}=$ polyhydramnios; $\mathrm{n}=$ normal; oligo=oligohydramnios; $\mathrm{IUD}=$ intrauterine death; $\mathrm{TP}=\mathrm{true}$ positive; $\mathrm{FP}=$ false positive; $\mathrm{CF}=$ cystic fibrosis; mis =misclassification; $\mathrm{MCA}=$ multiple congenital anomalies; $\mathrm{R}=$ multicystic kidney.

Delivery took place between 23 and 40 weeks of gestation, with preterm delivery ( $<37$ weeks) in 19 cases ( 65 per cent). Caesarean section was performed in four cases: in two cases because of a grossly enlarged fetal abdominal circumference with possible dystocia during vaginal delivery (Nos. 19 and 27); in one because of fetal distress (No. 17); and in another because of cervical dystocia during a trial of scar (No. 18).

Obstructive bowel disease was confirmed postnatally in 20 out of 29 cases (69 per cent), consisting of one case of oesophageal atresia, 12 cases of duodenal obstruction (duodenal atresia, $n=9$; annular pancreas, $n=2$; and paraduodenal hernia, $n=1$ ), and seven cases of small bowel obstruction (jejunal atresia, $n=3$; ileal atresia, $n=2$; meconium ileus and meconium pseudocysts because of cystic fibrosis, $n=1$; small bowel duplication, $n=1$ ). Table $V$ shows the association between additional sonographic and postnatal findings, abnormal karyotype, and fetal outcome in this group of 20 correctly diagnosed gastrointestinal anomalies. In six cases, anomalies other than obstructive bowel disease were diagnosed (misclassifications): multicystic kidney $(n=1)$ and multiple congenital anomalies $(n=5)$, one of which also represented a multicystic kidney. Three infants revealed no structural pathology (false positives).

As two terminations of pregnancy were requested and carried out and as perinatal death 
Table V-Additional sonographic and postnatal findings, karyotype, and outcome of the 20 correctly diagnosed gastrointestinal anomalies

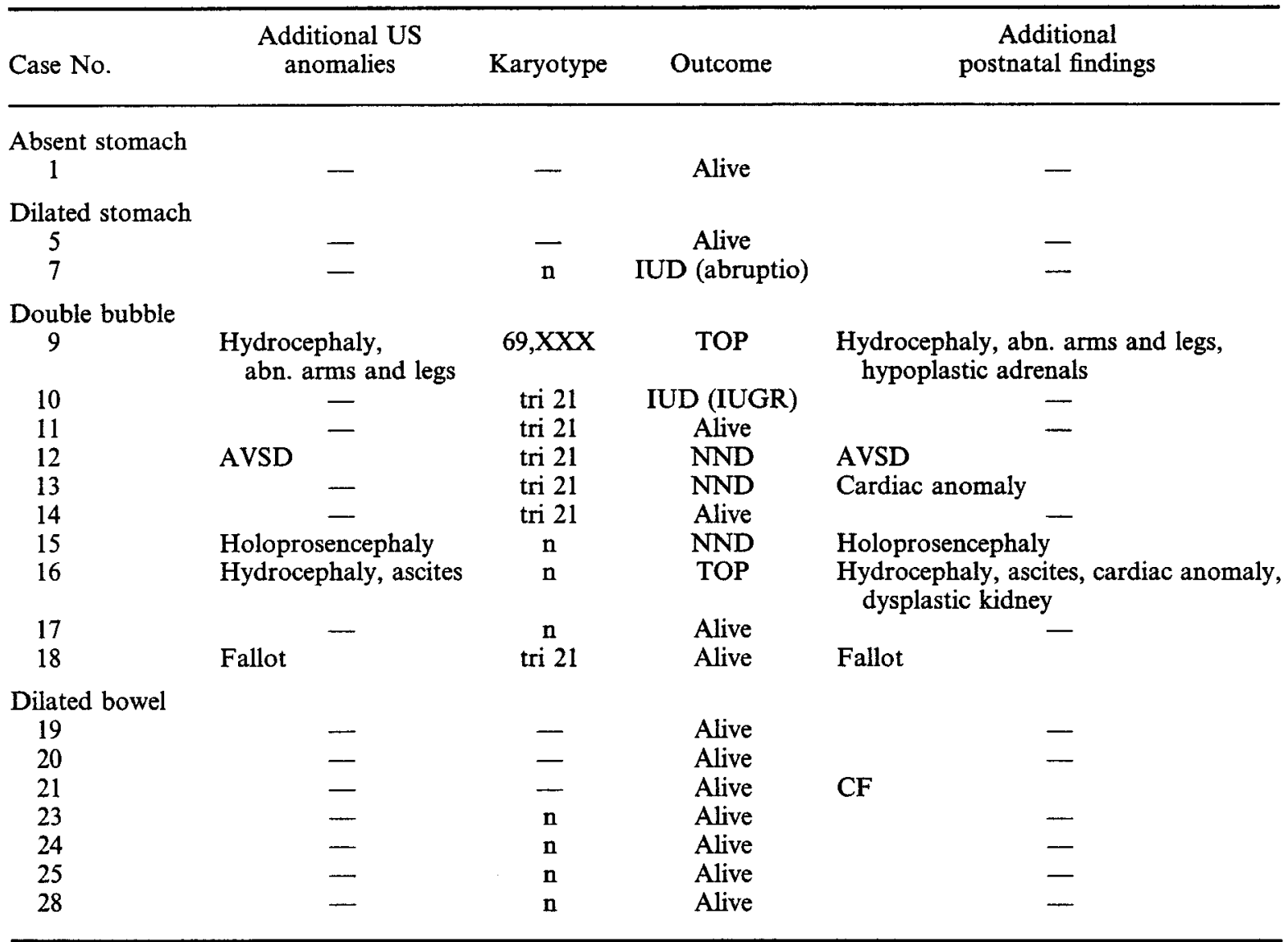

$\mathrm{n}=$ Normal; IUD = intrauterine death; IUGR = intrauterine growth retardation; $T O P=$ termination of pregnancy; tri $21=$ trisomy 21; NND=neonatal death; $\mathrm{AVSD}=$ atrioventricular septum defect; Fallot = tetralogy of Fallot; $C F=$ cystic fibrosis.

(intrauterine and neonatal mortality) occurred in eight cases and two infants died after the neonatal period in a further two cases, the overall survival rate is 59 per cent (17/29). However, when only the correctly diagnosed cases of obstructive bowel disease are included, the survival rate is 65 per cent $(13 / 20)$.

\section{DISCUSSION}

Gastrointestinal tract anomalies represent 15-20 per cent of all congenital anomalies (Jouppila and Kirkinen, 1984). Major parts of the digestive tract are nowadays easily accessible to ultrasound examination. The fetal oesophagus is normally not visualized at ultrasound examination due to its position behind the fetal trachea and heart and the absence of oesophageal content. Only in cases of oesophageal atresia without tracheo-oesophageal fistula is it sometimes possible to detect a blindending proximal oesophagus (Eyheremendy and Pfister, 1983).

Repeated absence of fetal stomach filling, particularly in the presence of polyhydramnios, could suggest oesophageal atresia (Eyheremendy and Pfister, 1983; Pretorius et al., 1988). However, the value of this ultrasonic marker appears to be limited, since gastric fluid secretion as such may cause distension of the stomach (Eyheremendy and Pfister, 1983). Moreover, in oesophageal atresia stomach filling may be expected because of the high association with tracheo-oesophageal fistula, through which amniotic fluid can pass into the 
fetal stomach (Hertzberg and Bowie, 1990). Also in cases of intrauterine growth retardation with or without oligohydramnios, absent stomach filling over a longer period is not an uncommon finding. In 60 per cent of oesophageal atresias other associated malformations have been reported (Holder et al., 1964; German et al., 1976; Hertzberg and Bowie, 1990). In our study, oesophageal atresia was only present in one out of four cases with repeated absence of stomach filling, and there were no associated anomalies. The remaining three infants displayed multiple anomalies unrelated to the gastrointestinal tract, which confirms a previous report in which a high incidence of non-gastrointestinal structural pathology was established in cases of non-visualization of the fetal stomach (Pretorius et al., 1988).

Stomach dilatation was observed in another four cases, twice accompanied by polyhydramnios. After delivery, one case of malrotation of the gut and one case of jejunal atresia with secondary distension of the stomach were diagnosed. However, in the remaining two infants no congenital anomalies were established. These two falsepositive findings highlight the marked variety in fetal stomach size in physiological circumstances as demonstrated by nomograms for fetal stomach size (Goldstein et al., 1987a).

On a transverse cross-section of the upper abdomen, the typical 'double bubble' sign is composed of an overdistended stomach in the left upper-abdominal quadrant connected with an enlarged duodenum on the right (Loveday et al., 1975). Particularly in the presence of polyhydramnios, this is suggestive of duodenal obstruction. Associated structural anomalies have been reported in 50 per cent of cases (Young and Wilkinson, 1968; Fonkalsrud et al., 1969; Jouppila and Kirkinen, 1984; Hertzberg and Bowie, 1990), whereas trisomy 21 has been diagnosed in 30 per cent of all duodenal atresias (Fonkalsrud et al., 1969; Fonkalsrud, 1979; Hertzberg and Bowie, 1990).

In the present study the 'double bubble' sign was associated with polyhydramnios in 80 per cent, structural pathology in 50 per cent, and an abnormal karyotype in 70 per cent of cases. Trisomy 21 constituted 86 per cent of all chromosomal anomalies. All ten cases of suspected duodenal obstruction were confirmed after delivery, i.e. eight infants with a duodenal atresia and two cases of an annular pancreas. Our present data confirm previous reports (Houlton et al., 1974; Loveday et al.,
1975; Duenhoelter et al., 1976; Boychuk et al., 1978; Balcar et al., 1984) that unlike abnormal stomach size, the 'double bubble' sign is highly predictive for obstructive bowel disease, i.e., duodenal obstruction, and necessitates a detailed ultrasonographic examination with subsequent fetal karyotyping.

The small bowel is normally seen as a more or less echo-dense area located centrally in the fetal abdomen. Peristalsis may be visible as early as 18 weeks of gestation, whereas after 28 weeks separate bowel loops can be visualized (Hertzberg and Bowie, 1990). An internal diameter of more than $7 \mathrm{~mm}$, especially in combination with strong peristaltic movements, is suggestive of obstruction (Nyberg et al., 1987).

Sometimes an unusual fetal small bowel pattern can be identified between 16 and 22 weeks of gestation, consisting of a well-defined homogeneously hyperechoic 'pseudomass' which later in pregnancy is replaced by a normal-moving fluidfilled small bowel. Manco et al. (1986) and Fakhry et al. (1986) have postulated that this phenomenon is a common normal variant and may be related to the increasing volume of amniotic fluid being swallowed during fetal development, thus exceeding the resorptive ability of the fetal stomach and duodenum with subsequent filling of the distal small bowel. Others have described an association with cystic fibrosis (Muller et al., 1985; Meizner, 1987; Caspi et al., 1988) and, more recently, with chromosomal abnormalities (Boue et al., 1988; Nyberg et al., 1990; Scioscia et al., 1992).

The fetal colon appears from as early as 22 weeks of gestation as a large hypoechoic tubular structure in the periphery of the fetal abdomen (Zilanti and Fernandez, 1983; Nyberg et al., 1987; Hertzberg and Bowie, 1990). Peristalsis is less clearly demonstrated than in the small bowel (Zilanti and Fernandez, 1983). The mean diameter of the normal colon increases approximately linearly with gestational age until $18 \mathrm{~mm}$ or more (Goldstein et al., 1987b; Nyberg et al., 1987). However, like the fetal stomach, variation in size is considerable with a substantial overlap between physiologically and pathologically distended colon. DeLorimier et al. (1969) and Nixon and Tawes (1971) observed associated anomalies in only 7 per cent of all bowel atresias, which is consistent with the hypothesis that bowel atresia is an acquired defect due to an in utero vascular accident, whereas oesophageal and duodenal atresia should result from an early embryonic 
insult (Louw and Barnard, 1955; Touloukian, 1978; Hertzberg and Bowie, 1990).

Dilated bowel loops were established in 11 cases, six of which were associated with polyhydramnios and two with oligohydramnios. Bowel obstruction was confirmed in seven infants, i.e., duodenal atresia $(n=1)$, jejunal atresia $(n=2)$, ileal atresia $(n=2)$, cystic fibrosis with meconium ileus and meconium pseudocysts $(n=1)$, and small bowel duplication $(n=1)$. None of them revealed associated structural anomalies. Small bowel obstruction can be associated with cystic fibrosis. This could be brought up when counselling couples. Estroff et al. (1992) reported a relatively high incidence of 36 per cent $(4 / 11)$ in their population of correctly diagnosed dilated bowel loops, while in our seven correctly diagnosed bowel obstructions cystic fibrosis was only diagnosed once. In the remaining four cases there were two infants with multiple non-gastrointestinal anomalies, one with a multicystic kidney, and one with no malformations. None of these 11 infants displayed an abnormal karyotype.

Although we did not intend to exclude colonic obstructions, no fetuses with colonic obstructions were seen in our study. This is supported by Hertzberg and Bowie (1990), who report that colonic obstructions have only occasionally been reported antenatally while most cases do not present until after birth.

The differential diagnosis of suspected bowel obstruction based on intra-abdominal echolucent cystic abnormalities consists of urinary tract anomalies (multicystic kidneys, hydronephrosis, and/or hydroureter), hydrometrocolpos, and other cystic anomalies such as choledochal, mesenterial, omental, and ovarian cysts (Zilanti and Fernandez, 1983; Hertzberg and Bowie, 1990). Sometimes it is possible to simulate a double bubble-like sign by scanning the fetal trunk in a coronal plane causing bisection of a normal fetal stomach (Gross and Filly, 1982). However, suspicion of a gastrointestinal obstruction should arise when two or more cystic lesions in the presence of normal kidneys are seen at ultrasound examination, especially when they are interconnected, display increased peristalsis, or are associated with polyhydramnios.

Although polyhydramnios is a non-specific and insensitive marker, it was present in 75 per cent of our correctly diagnosed gastrointestinal tract obstructions and it was equally divided between oesophageal and duodenal obstructions $(10 / 13=77$ per cent) and small bowel obstructions (5/7 $=71$ per cent). In obstructive bowel disease, polyhydramnios develops as a result of proximal obstruction and when the amniotic fluid swallowed exceeds the resorptive capacity of the remaining available intestinal surface (Nelson et al., 1982), i.e., through regurgitation or a decrease in fluid passage through the fetal gut (Barss et al., 1984). It usually develops during the late second or third trimester of pregnancy. The late appearance of polyhydramnios and dilated bowel is determined by fetal swallowing, which only starts at 16-17 weeks of gestational age (Pritchard, 1966) and by the increased formation and turnover rate of amniotic fluid in the second and third trimesters (Jouppila and Kirkinen, 1984). Of the 15 correctly diagnosed gastrointestinal obstructions which were associated with polyhydramnios, this was established in the third trimester in all 15 cases. This explains the late referral to our tertiary centre.

Finally, within the group of correctly diagnosed gastrointestinal anomalies $(n=20)$, all seven abnormal karyotypes and six out of seven perinatal deaths were associated with the 'double bubble' sign, which points to the need for a careful search for associated anomalies and subsequent prenatal karyotyping in this particular sonographic abnormality.

Although the numbers are small, a low incidence of associated congenital and chromosomal anomalies resulting in a good fetal outcome was demonstrated in the other three categories of suspected gastrointestinal obstruction.

\section{REFERENCES}

Balcar, I., Grant, D.C., Miller, W.A., Bieber, F.A. (1984). Antenatal detection of Down syndrome by sonography, Am. J. Roentgenol., 143, 29-30.

Barss, V.A., Benacerraf, B.R., Frigoletto, F.D., Jr (1985). Antenatal sonographic diagnosis of fetal gastrointestinal malformations, Pediatrics, 76, 445449.

Boue, A., Muller, F., Briard, M.L., Boue, J. (1988). Interest of biology in the management of pregnancies where a fetal malformation has been detected by ultrasonography, Fetal Ther., 3, 14-23.

Boychuk, R.B., Lyons, E.A., Goodhand, T.K. (1978). Duodenal atresia diagnosed by ultrasound, Radiology, $127,500$.

Campbell, S., Wilkin, D. (1975). Ultrasonic measurement of fetal abdominal circumference in estimation of fetal weight, Br. J. Obstet. Gynaecol., 82, 689-697. 
Caspi, B., Elchalal, U., Lancet, M., Chemke, J. (1988). Prenatal diagnosis of cystic fibrosis: ultrasonographic appearance of meconium ileus in the fetus, Prenat. Diagn., 8, 379-382.

DeLorimier, A.A., Fonkalsrud, E.W., Hays, D.M. (1969). Congenital atresia and stenosis of the jejunum and ileum, Surgery, 65, 819-827.

Duenholter, J.H., Santos-Ramos, R., Rosenveld, C.R., Coln, C.D. (1976). Prenatal diagnosis of gastrointestinal tract obstruction, Obstet. Gynecol., 47, 618-620.

Estroff, J.A., Parad, R.B., Benacerraf, B.R. (1992). Prevalence of cystic fibrosis in fetuses with dilated bowel, Radiology, 183, 677-680.

Eyheremendy, E., Pfister, M. (1983). Antenatal real-time diagnosis of esophageal atresias, J. Clin. Ultrasound, 11, 395-397.

Fakhry, J., Reiser, M., Shapiro, L.R., Schechter, A., Pait, L.P., Glennon, A. (1986). Increased echogenicity in the lower fetal abdomen: a common normal variant in the second trimester, $J$. Ultrasound Med., 5, 489492.

Fonkalsrud, E.W. (1979). Duodenal atresia or stenosis. In: Bergsma, D. (Ed.). Birth Defects Compendium, 2nd edn, New York: Alan R. Liss, 350.

Fonkalsrud, E.W., DeLorimier, A.A., Hays, D.M. (1969). Congenital atresia and stenosis of the duodenum. A review compiled from the members of the Surgical Section of the American Academy of Pediatrics, Pediatrics, 43, 79-83.

German, J.C., Mahour, G.H., Woolley, M.M. (1976). Esophageal atresia and associated anomalies, $J$. Pediatr. Surg., 11, 299-306.

Goldstein, I., Reece, E.A., Yarkoni, S., Wan, M., Green, J.L.J., Hobbins, J.C. (1987a). Growth of the fetal stomach in normal pregnancies, Obstet. Gynecol., 70, 641-644.

Goldstein, I., Lockwood, C., Hobbins, J.C. (1987b). Ultrasound assessment of fetal intestinal development in the evaluation of gestational age, Obstet. Gynecol. 70, 682-686.

Gross, B.H., Filly, R.A. (1982). Potential for a normal fetal stomach to simulate the sonographic 'double bubble' sign, J. Can. Assoc. Radiol., 33, 39-40.

Hertzberg, B.S., Bowie, J.D. (1990). Fetal gastrointestinal abnormalities, Radiol. Clin. North Am., 28, 101114.

Holder, T.M., Cloud, D.T., Lewis, J.E., Jr, Pilling, G.P. (1964). Esophageal atresia and tracheoesophageal fistula. A survey of its members by the surgical section of the American Academy of Pediatrics, Pediatrics, $34,542-549$.
Houlton, M.C.C.C., Sutton, M., Aitken, J. (1974). Antenatal diagnosis of duodenal atresia, J. Obstet. Gynaecol. Br. Commonw., 81, 818-821.

Jouppila, P., Kirkinen, P. (1984). Ultrasonic and clinical aspects in the diagnosis and prognosis of congenital gastrointestinal anomalies, Ultrasound Med. Biol., 10, 465-472.

Louw, J.H., Barnard, C.N. (1955). Congenital intestinal atresia. Observations on its origin, Lancet, 2, 1065.

Loveday, B.J., Barr, J.A., Aitken, J. (1975). The intrauterine demonstration of duodenal atresia by ultrasound, Br. J. Radiol., 48, 1031-1032.

Manco, L.G., Nunan, F.A., Jr, Sohnen, H., Jacobs, E.J. (1986). Fetal small bowel simulating an abdominal mass at sonography, J. Clin. Ultrasound, 14, 404-407.

Meizner, I. (1987). Letter to the editor, J. Clin. Ultrasound, 15, 494-495.

Muller, F., Aubry, M.C., Gasser, B., Duchatel, F., Boue, J., Boue, A. (1985). Prenatal diagnosis of cystic fibrosis. II. Meconium ileus in affected fetuses, Prenat. Diagn., 5, 109-117.

Nelson, L.H., Clark, C.E., Fishburne, J.I., Urban, R.B., Penry, M.F. (1982). Value of serial sonography in the in utero detection of duodenal atresia, Obstet. Gynecol., 59, 657-660.

Nixon, H.H., Tawes, R. (1971). Etiology and treatment of small intestinal atresia: analysis of a series of 127 jejunoileal atresias and comparison with 62 duodenal atresias, Surgery, 69, 41-51.

Nyberg, D.A., Resta, R.G., Luthy, D.A., Hickok, D.E., Mahony, B.S., Hirsch, J.H. (1990). Prenatal sonographic findings of Down syndrome: review of 94 cases, Obstet. Gynecol., 76, 370-377.

Pretorius, D.H., Gosink, B.B., Clautice-Engle, T., Leopold, G.R., Minnick, C.M. (1988). Sonographic evaluation of the fetal stomach: significance of nonvisualisation, Am. J. Roentgenol., 151, 987-989.

Pritchard, J.A. (1966). Fetal swallowing and amniotic fluid volume, Obstet. Gynecol., 28, 606-610.

Scioscia, A.L., Pretorius, D.H., Budorick, N.E., Cahill, T.C., Axelrod, F.T., Leopold, G.R. (1992). Secondtrimester echogenic bowel and chromosomal abnormalities, Am. J. Obstet. Gynecol., 167, 889-894.

Touloukian, R.J. (1978). Intestinal atresia, Clin. Perinatol., 5, 3-18.

Young, D.G., Wilkinson, A.W. (1968). Abnormalities associated with neonatal duodenal obstruction, Surgery, 63, 832-836.

Zilanti, M., Fernandez, S. (1983). Correlation of ultrasonic images of fetal intestine with gestational age and fetal maturity, Obstet. Gynecol., 62, 569-573. 